\title{
Coastal Vulnerability to Sea Level Rise: A Spatio-Temporal Decision Making Tool
}

\author{
Oz Sahin $^{1}$, Sherif Mohamed ${ }^{1}$ \\ ${ }^{1}$ School of Engineering, Griffith University, Gold Coast, Queensland, Australia \\ o.sahin@griffith.edu.au, s.mohamed@griffith.edu.au
}

\begin{abstract}
Due to uncertainty in the timing and magnitude of Sea Level Rise (SLR) impacts, it is difficult to determine whether taking a specific action to prepare for SLR is justified. The dilemmas confronting decision makers are: when, where and how to adapt to SLR. To address these issues, this research introduces a recently developed model linking Geographical Information Systems (GIS) with System Dynamics (SD) modelling to present realistic time series scenarios of SLR across coastal communities. The hybrid GIS-SD model provides a multifaceted assessment by going beyond detailing year specific land use impacts through linking these outputs with socio-economic SD modules. As a result, the model provides the potential to address temporal and spatial problems concurrently. The methodology formulated from this assessment process, could potentially be utilised by coastal communities to identify and evaluate effective adaptation alternatives for reducing SLR impacts, and to inform long-term decision making.
\end{abstract}

Keywords - Decision making, Dynamic modelling, SLR, Vulnerability Assessment.

\section{INTRODUCTION}

There is general consensus among scientists that the climate is significantly and inevitably changing. Warming of the climate system is now unequivocal [1]. SLR is one of the most recognized possible impacts of changing climate in the literature. The Intergovernmental Panel on Climate Change (IPCC) estimates that the global-mean sea level may rise between 0.18 and $0.59 \mathrm{~m}$ by 2100 , not including 10 to $20 \mathrm{~cm}$ possible contribution from the Greenland and Antarctica Ice Sheets [2]. However, Rahmstorf's study published after the IPCC suggests an even higher range of 0.5 to $1.4 \mathrm{~m}$ by 2100 [3]. Moreover, SLR is expected to continue for many centuries, even if Greenhouse Gas (GHG) concentrations are stabilized at relatively low levels $[4,5]$.

Considerable human activity and population growth takes place in coastal areas. It is well known that SLR will have profound implications for many coastal populations and the systems on which they depend [6]. Existing nearcoastal populations, within $100 \mathrm{~km}$ of a shoreline and within $100 \mathrm{~m}$ sea level, are estimated at 1.2 billion people, with an average density nearly 3 times higher than the global average density [7]. SLR, at the estimated rate, will not pose an immediate threat to coastal areas; however a higher sea level will provide a higher base for storm surges to build upon. Thus, storm surges occurring in conditions of higher mean sea levels will enable inundation and damaging waves to penetrate further inland, increasing flooding, erosion and the subsequent impacts on built infrastructure and natural ecosystems [8]. As a result, SLR will exacerbate the vulnerability of coastal populations and ecosystems via permanent inundation of low-lying regions, inland extension of episodic flooding, increased beach erosion and saline intrusion of aquifers [9]. These physical impacts may result in socioeconomic impacts on the coastal zone such as loss of properties and coastal habitats, and loss of tourism, recreation and transportation functions. Thus, SLR will intensify the stress on coastal zones where adaptive capacities of natural and social systems have been weakened.

\section{PROBLEM DEFINITION}

There are numerous studies which focus on assessing coastal vulnerability on national and global scales. However availability of regional scale comprehensive vulnerability assessments studies, which are required by local stakeholders to design adaptation strategies at local level, are limited $[10,11]$. Besides, due to uncertainty in climate change predictions, traditionally, coastal vulnerability assessments and most town planning activities are based on an assumption that sea level will remain constant in the future. However, a changing sea level means that the baseline upon which current vulnerability is being assessed is also changing. As a result, planning our cities under the conditions of SLR becomes more difficult when considering longer planning horizons. It is essential to consider coastal dynamics under various scenarios to deal with the uncertainties when preparing our cities for the future. Therefore, there is a need to understand the impacts of SLR, how to manage a response system and how to plan our cities[12].

Societies need to respond to SLR in order to reduce adverse impacts and improve adaptive capacity. Nevertheless, due to uncertainties in future climate change projections, vulnerability assessment and adaptation are challenging issues in vulnerability and adaptation research. Therefore, developing an adequately flexible and well structured method is essential so as to provide the vulnerability information required for designing more effective adaptation strategies, as well as better management plans for reducing the adverse effects of SLR.

In light of the above observations and studies, this research focuses on assessing present and future 
vulnerability of waterfront properties and populations in coastal areas to SLR and storm surge events. It subsequently examines and evaluates alternative adaptation options for reducing the adverse effects of SLR in the selected study area.

\section{APPROACH}

\section{A. Vulnerability Assessment (VA)}

The IPCC defines vulnerability as: "the degree to which a system is susceptible to, and unable to cope with, adverse effects of climate change, including climate variability and extremes. Vulnerability is a function of the character, magnitude, and rate of climate change and variation to which a system is exposed, its sensitivity, and its adaptive capacity" [13]. The concepts of adaptation, adaptive capacity, vulnerability, resilience, exposure and sensitivity are interrelated and have wide applications for global change science [14]. Differences in exposure to the various direct effects of climate change and different sensitivities to these direct effects lead to different potential impacts on the system of interest. The system's adaptive capacity then determines its vulnerability to these potential impacts. These causal relationships are illustrated by the causal loop diagram (CLD) in Fig. 1.

The primary goal of VA is to produce recommendations on actions to reduce vulnerability. It includes both the present and future vulnerability assessments and available adaptation options. Therefore, the research focuses on natural and socio-economic systems that are already vulnerable to climate variability by analysing their current conditions to provide a reference map to compare future conditions. It then analyses the systems under various scenarios to identify how climate variability will affect the already troubled systems over time. Vulnerability in this research is considered as people-at-risk and loss of residential property due to exposure to SLR and related storm surge.

The degree to which coastal land is at risk of flooding from storm surges is determined by a number of morphological and meteorological factors, including: coastal slope and wind and wave characteristics [15]. Additionally, spatial dependency is a key concept for understanding and analysing spatial events. According to Waldo Tobler, the first law of geography is that everything is related to everything else, but near things are more related than distant things [16]. Generalizing, we can state that most of the occurrences, natural or social, present among themselves a relationship that depends on distance. What does this principle imply? If proximity of a property to the coast would increase or decrease, so would the risk it is exposed to due to SLR.

The critical vulnerability of coastal areas to coastal storms (in the short term) and SLR (in the long term) works through flooding. The extent and timing of coastal flooding and its impacts under various scenarios will be assessed in terms of two indicators: (1) Population within the 1/100 year flood level and, (2) Number of residential properties within the 1/100 year flood level.

Three SLR scenarios are considered in this research: the IPCC lower and upper range projections (including 10-20 $\mathrm{cm}$ ice sheet contribution) and Rahmstorf's estimation together with additional local adjustment.

Key data sets used in this research are; $5 \mathrm{~m}$ digital elevation model (DEM) with10 cm vertical accuracy, mean and high water level data, land use data, surface flood level data and population data.

For case study analyses, the City of the Gold Coast located in South-East Queensland, Australia has been selected. The area encompasses a diverse range of features including sandy beaches, estuaries, coastal lagoons and artificial waterways and is highly vulnerable to SLR. In this region, the maximum tidal range is $1.8 \mathrm{~m}$, and on average, the coast is affected by 1.5 cyclones each year [17]. Many of the residential areas in the city are filled to the 1:100 year flood level [18].

\section{B. Assessment Tools}

Traditional modelling approaches focus on either temporal or spatial variation, but not both. However, it is the space-time integration that provides the explanatory power to understand and predict reality. Additionally, there is important feedback between time and space therefore they have to be examined together [19].

Considering the complexity and dynamic nature of coastal systems with many feedbacks and dependencies changing over time, this research focuses on modelling temporal and spatial variations of coastal processes in assessing vulnerability of the systems to SLR and storm surges. In order to achieve this, two modelling approaches, namely; System Dynamics (SD) modelling and Geographical Information Systems (GIS), are combined.

System Dynamics (SD) is a powerful methodology and computer simulation modelling technique for understanding the behaviour of complex systems over time. It deals with internal feedback loops and time delays that affect the behaviour of the entire system. SD modelling is becoming increasingly popular in addressing complex natural processes. SD is used for; modelling sealevel rise in a coastal area [20]; modelling environmental issues [21]; simulating flooding in the Red River basin Canada [19]; US flood policy analyses [22] and evaluating adaptation options for responding to coastal flooding in Metro Boston USA [23].

Geographic Information System (GIS) is used for geospatial data management and analysis, image processing, graphics/maps production, spatial modelling, and visualization. Owing to its capability of analysing spatial data, the GIS approach has been widely used in vulnerability and impact analyses. Many researchers used GIS in coastal vulnerability assessments [24-29]. 


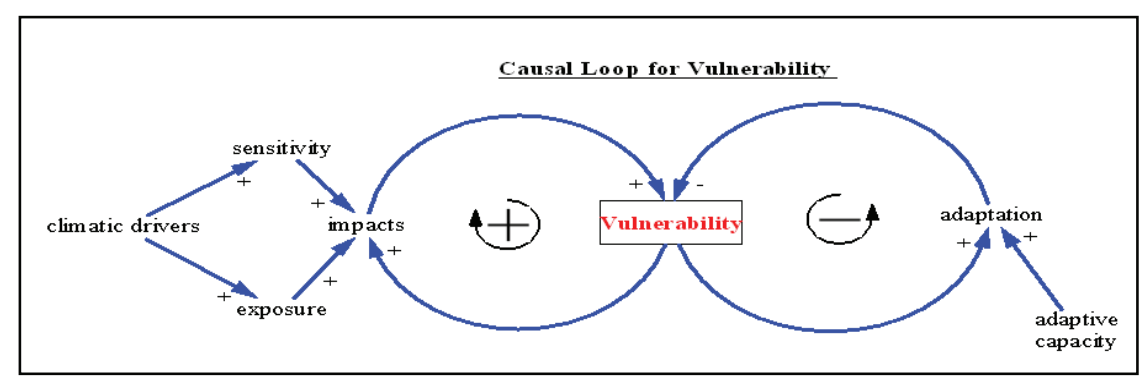

Fig. 1. Causal Loop Diagram for Vulnerability

Both approaches have their own shortcomings. Although temporal process is adequately represented in SD models, spatial dimensions, however are not explicitly dealt with. Conversely, GIS, while having strong capabilities of modelling the spatial dimensions of the real world, GIS has difficulties in handling temporal dimensions.

By considering weaknesses and strengths of both, in this research, the SD and the GIS approaches are coupled by linking them through a dynamic data exchange (DDE). As a result, the new model becomes capable to provide the potential to simultaneously address temporal and spatial problems. While GIS provides spatial information to the SD, the SD model will capture changes in spatial features over time and feed them back to GIS. As a result, the dynamic nature of coastal processes and their interactions can be captured in time and space.

\section{Inundation Modelling}

Inundation risk is best expressed as the likelihood of exceeding a given level of tide, surge and flood height over a particular time horizon. Inundation events vary in frequency and magnitude. Frequency is measured as average recurrence intervals of events. For example, a 1in-100 year flood is the flood height that is expected to be exceeded on average once every 100 years. Magnitude refers to a given level of flood height. Generally, the less frequent the event generally the larger in size it is.

Coastal risks have traditionally been assessed with an assumption that the mean sea level will remain constant. However, sea level is changing. Consequently the baseline upon which current inundation risk is being calculated is also changing as seen in Fig. 2. Depending on the rate of SLR, an area that is now subject to a 1 in 100 year flood risk may in time face more frequent flood

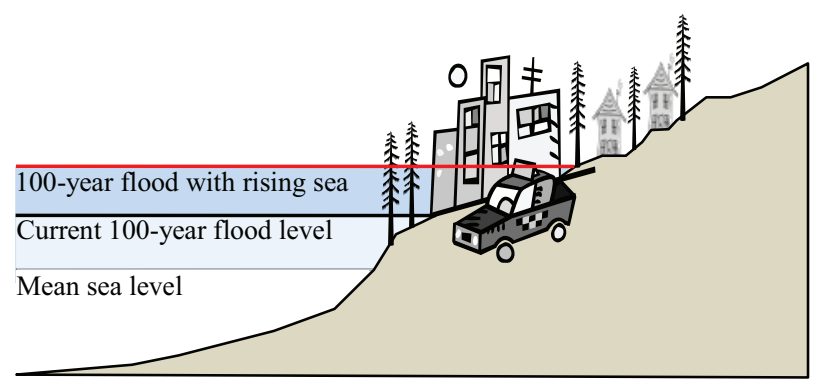

Fig.2 Relationship between SLR and a 100 Year Flood Level events, for instance; an event that currently happens every 100 years would happen annually in 2100 . As a result, the problem of planning for longer horizons becomes more difficult due to the changing baseline.

This research models the coastal inundation to analyse this dynamic and complex real-world problem in order to make predictions about what might happen with different actions under various scenarios. A relatively simple modelling approach is used to determine the areas that would be inundated at certain SLR and storm conditions. The model simulates changes in sea level and inundates all land areas at an elevation below the simulated sea level. In doing so, some degree of simplification has to be made for reducing the reality to manageable proportions, since the real world is too rich for all components and relationships to be considered.

As shown in Fig. 3, the condition of the system is described by three state variables that are measures of system components whose values vary with time. The Sea Level is an exogenous or driving variable causing changes in both the Elevation and the Cover variables over time. Besides, a change in one state variable effects a change in the others if they are connected. Thus, the modelled system acts as a single unit through the interrelations among its components. In environmental systems, modelling the behaviour of process in space is just as important as modelling time. Therefore, both dimensions are included in the model by linking GIS to the SD model through a DDE (Fig. 3).

The model calculates potentially inundated areas, based on elevation, states of adjacent cells states (Water or Land) and their proximity to Water cells. For this, initial elevation value and cover type of each cell are determined in GIS and get transferred to the SD model. Then, in SD, elevation and cover type value of each cell is recalculated depending on the sea level at the next time step.

As SLR is simulated, the flood water spreads from one cell to another and the total number of inundated cells increases accordingly. Subsequently, for each incremental SLR, total inundated surface area is computed by summing the number of inundated cells.Fig. 3 shows three different stages of an area shown as $20 \times 20$ grid cells that are inundated over time under $1 \mathrm{~m}$ SLR scenario. The dark coloured cells represent Water $(W)$ or inundated cells, while the light coloured cells show Land $(L)$ cells. For example; a cell at a location $\mathrm{x}_{i}, \mathrm{y}_{j}$ will be flooded if two conditions are satisfied: 


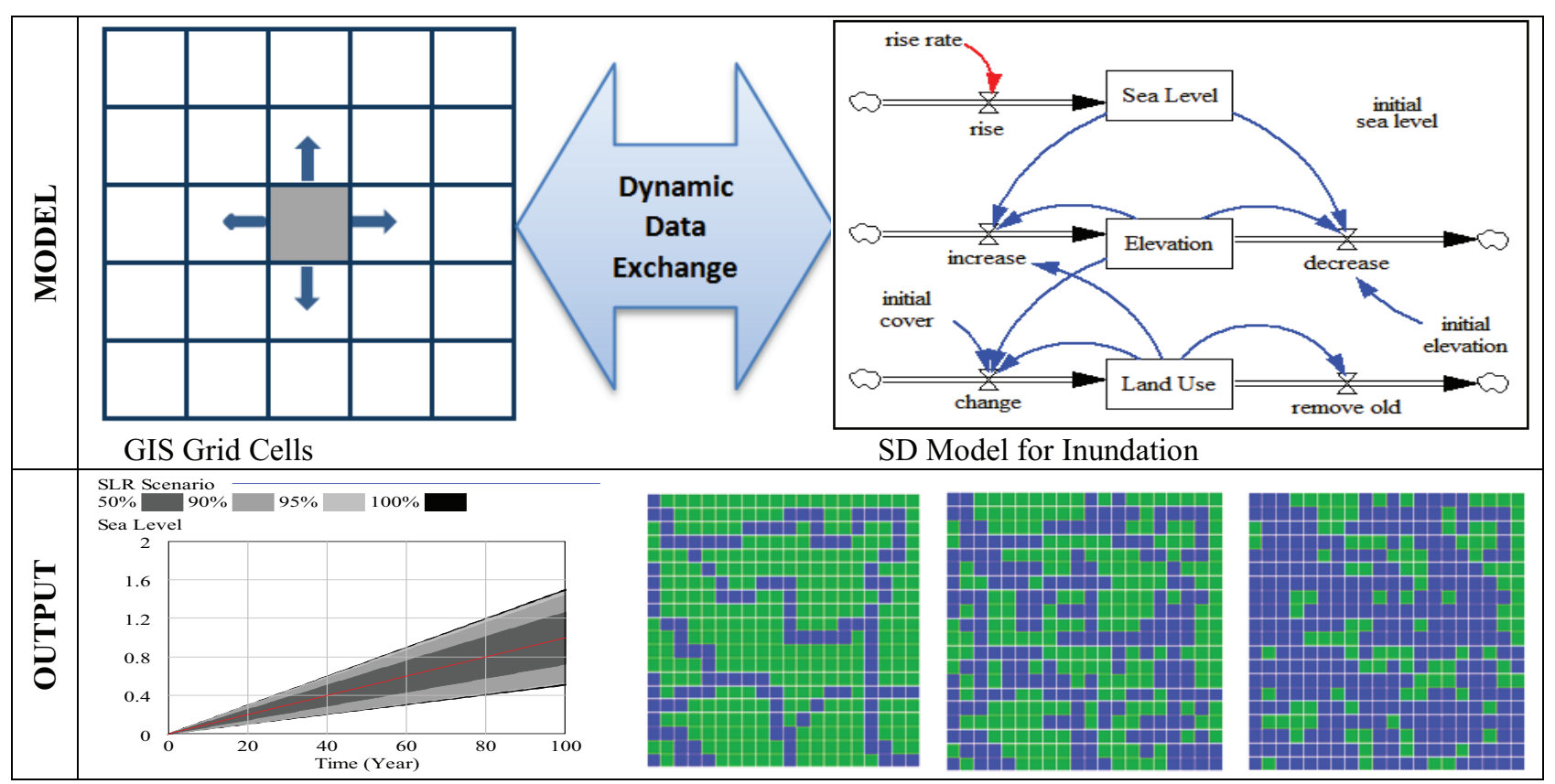

Fig. 3 Coupling SD-GIS for Modelling Coastal Inundation.

(1) Elevation of the cell $\leq$ adjacent cells and

(2) The cell cover type is L and at least the cover type of one adjacent cell is $\mathrm{W}$.

The following equation describes how the model predicts flood water diffusion from one cell to another:

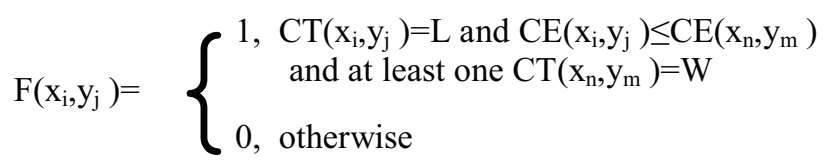

Where: $F$ can be, either flooded (1) or not flooded (0); $C E$ is cell elevation; $C T\left(\mathrm{x}_{\mathrm{i}}, \mathrm{y}_{\mathrm{j}}\right)$ is cover type, either land $L$ or water $W ; C T\left(\mathrm{x}_{n}, \mathrm{y}_{m}\right)$ refers to adjacent cells cover types, either land $L$ or water $W$ and $(n, m)$ refers to all adjacent cells to $i, j$ (i.e.: $i, j-1, i, j+1, i+1, j$ and $i-1, j$ ).

\section{DISCUSSION}

Coastal regions are highly vulnerable to climate change. Therefore developing and implementing effective adaptation options are crucial for their future development. However, there is uncertainty in the timing, duration, spatial location and extent of SLR and storms. So, while the probability and magnitude of a particular flood event that may occur within the next 100 years can be estimated, it is not possible to say when exactly this will happen.

The complexity that arises from climate, coastal systems and their interactions in space and time can easily overwhelm the ability of decision makers to thoroughly investigate the outcomes of adaptation alternatives. Dilemmas confronting decision makers are: how to adapt and when to adapt to SLR. Determining how and when specific actions should be taken is not simple, due to uncertainty in the timing and magnitude of SLR impacts [12]. To facilitate these decisions, policy makers require credible scientific data and information.

By considering the uncertain nature of projected changes in climate and addressing these dilemmas, this research introduces a dynamic model for a comprehensive vulnerability assessment of coastal areas focusing on changes in sea level, therefore assisting decision makers in identifying and evaluating effective adaptation alternatives for reducing climate change impacts. The model also provides a number of spatial maps of inundation at regional scale which show areas and population at risk on various time scales. These maps can be very useful for increasing public awareness as well as planning purposes.

The model is dynamic in terms of capturing feedbacks and dependencies changing over time and it considers spatial characteristics of the study area. It is also flexible and modular therefore other elements affecting coastal systems can be integrated as needed.

Finally, all research has limitations and this one is no exception. This research considers only impacts from inundation and coastal flooding due to storm surge and SLR. All other impacts, such as flooding due to heavy precipitation, are disregarded. Additionally, determining an inundation area with less than $10 \mathrm{~cm}$ elevation is not possible since vertical resolution of DEM data sets is 10 $\mathrm{cm}$.

\section{ACKNOWLEDGMENT}

Funding received from the Centre for Infrastructure Engineering Management and Griffith Climate Change Response Program in facilitating attendance at this conference is gratefully acknowledged. 


\section{REFERENCES}

[1] Solomon, S., et al., Summary for Policymakers. IN Climate Change 2007: The Physical Science Basis. Contribution of Working Group I to the Fourth Assessment Report of the Intergovernmental Panel on Climate Change 2007. p. 1-18.

[2] Meehl, G.A., et al., Global Climate Projections. IN Climate Change 2007: The Physical Science Basis. Contribution of Working Group I to the Fourth Assessment Report of the Intergovernmental Panel on Climate Change. 2007, The IPCC: Cambridge, UK and New York, NY, USA.

[3] Rahmstorf, S., A Semi-Empirical Approach to Projecting Future Sea-Level Rise. Science, 2007. 315(5810): p. 368370.

[4] Nicholls, R.J. and J.A. Lowe, Benefits of mitigation of climate change for coastal areas. Global Environmental Change, 2004. 14(3): p. 229-244.

[5] Church, J.A., et al., Changes in Sea Level. IN The Scientific Basis. Contribution of Working Group I to the Third Assessment Report of the Intergovernmental Panel on Climate Change. 2001, The IPCC: Cambridge, U.K. and New York, NY, USA.

[6] Brooks, N., J. Hall, and R. Nicholls, Sea-Level Rise: Coastal Impacts and Responses. 2006, Berlin: The German Advisory Council on Global Change (WBGU)

[7] Small, C. and R.J. Nicholls, A Global Analysis of Human Settlement in Coastal Zones. Journal of Coastal Research, 2003. 19(3): p. 584-599.

[8] Pearce, K., et al., Climate change in Australia Technical Report 2007. 2007.

[9] McLean, R.F., et al., Coastal Zones and Marine Ecosystems. IN Climate Change 2001: Impacts, Adaptation, and Vulnerability 2001: Cambridge, UK and NY, USA.

[10] Torresan, S., et al., Assessing coastal vulnerability to climate change: comparing segmentation at global and regional scales. Sustainability Science, 2008. 3(1): p. 45-65.

[11] Cooper, M.J.P., M.D. Beevers, and M. Oppenheimer, The potential impacts of sea level rise on the coastal region of New Jersey, USA. Climatic Change, 2008. 90(4): p. 475492.

[12] Sahin, O. and S. Mohamed. Decision Dilemmas for Adaptation to Sea Level Rise: How to, when to? IN IEEE 2009 International Conference on Industrial Engineering and Engineering Management. 2009. Hong Kong: IEEE.

[13] Parry, M., et al., IPCC, 2007: Climate Change 2007: Impacts, Adaptation and Vulnerability. Contribution of Working Group II to the Fourth Assessment Report of the Intergovernmental Panel on Climate Change. 2007, Intergovernmental Panel on Climate Change 2007: Cambridge, UK. p. 976.

[14] Smit, B. and J. Wandel, Adaptation, adaptive capacity and vulnerability. Global Environmental Change, 2006. 16 p. 282-292.

[15] Klein, R.J.T. and R.J. Nicholls, Coastal zones IN Handbook on Climate Change Impact Assessment and Adaptation Strategies. 1998, United Nations Environment Programme and Institute for Environmental Studies Amsterdam and Nairobi.

[16] Tobler, W.R., A Computer Movie Simulating Urban Growth in the Detroit Region. Economic Geography, 1970. 46(2): p. 234-240.

[17] Boak, L., J. McGrath, and L.A. Jackson. A Case Study: The Northern Gold Coast Beach Protection Strategy. IN 27th International Conference on Coastal Engineering. 2001. Sydney, Australia: American Society of Civil Engineers.
[18] Betts, H., Flood damage analysis using GIS at Gold Coast Council. Australian Journal of Emergency Management 2002. 17(1): p. 33-37.

[19] Ahmad, S. and S.P. Simonovic, Spatial System Dynamics: New Approach for Simulation of Water Resources Systems. Journal of Computing in Civil Engineering, ASCE, 2004. 18(4): p. 331-340.

[20] Ruth, M. and F. Pieper, Modeling spatial dynamics of sealevel rise in a coastal area. System Dynamics Review, 1994. 10(4): p. 375-389.

[21] Ford, A., Modelling the Environment: An Introduction to System Dynamics Modelling of Environment Systems. 1999, Washington DC, USA: Island Press. 402.

[22] Deegan, M.A. Defining the Policy Space for Disaster Management: A System Dynamics Approach to U.S. Flood Policy Analysis. IN The 24th International Conference of the System Dynamics Society. 2006. The Netherlands.

[23] Kirshen, P., K. Knee, and M. Ruth, Climate Change and Coastal Flooding in Metro Boston: Impacts and Adaptation Strategies. Climatic Change, 2008. 90: p. 453-473.

[24] Al-Jeneid, S., M. Bahnassy, and S.N.M.E. Raey, Vulnerability assessment and adaptation to the impacts of sea level rise on the Kingdom of Bahrain. Mitigation and Adaptation Strategies for Global Change, 2008. 13(1): p. 87104.

[25] Gravelle, G. and N. Mimura, Vulnerability assessment of sea-level rise in Viti Levu, Fiji Islands. Sustainability Science, 2008. 3(2): p. 171-180.

[26] Lathrop, R.G. and A. Love, Vulnerability of New Jersey's Coastal Habitats to Sea Level Rise and American Littoral Society. 2007, Grant F. Walton Center for Remote Sensing \& Spatial Analysis Rutgers University New Brunswick, NJ, USA.

[27] Szlafsztein, C.F. and H. Sterr, Climate change, Sea-level rise and Coastal Natural Hazards: A GIS-Based Vulnerability Assessment, State of Pará, Brazil. Journal of Coastal Conservation, 2007. 11 (1): p. 53-66.

[28] Hennecke, W.G. and P.J. Cowell, GIS Modeling of Impacts of an Accelerated Rate of Sea-Level Rise on Coastal Inlets and Deeply Embayed Shorelines. Environmental Geosciences, 2000. 7(3): p. 137-148.

[29] Poulter, B. and P.N. Halpin, Raster modelling of coastal flooding from sea-level rise. International Journal of Geographical Information Science, 2008. 22(2): p. 167 182. 